\title{
In vitro screening of herbal plant extracts on human nail fungus
}

\author{
K Niranjan* \\ Department of Botany, Faculty of Science, University of Jaffna, Sri Lanka
}

\begin{abstract}
Nowadays nail infections are commonly found among people worldwide. The disease called onychomycosisis usually caused by dermatophytic fungus. During this study pathogen was isolated from infected nail (scaly nail with white and yellow colour patches) using BD Dermatophyte Test Medium Agar. The pure culture of the pathogen was obtained and its morphological characters were recorded. Objective of this study is to isolate and identify the pathogen and find out potential herbal remedy for that. Five medicinal plants, Phyla nodiflora, Lawsonia inermis, Cassia fistula, Vernonia cinerea and Aristolochia bracteolate were selected and antifungal chemical remedy Clotrimazol and distilled water were used as positive and negative control against the pathogen under in vitro condition. Water and ethanol leaf extracts of each plants were prepared separately. Inhibitory effect of plant extracts against the pathogen was screened by poison food technique at various time intervals ( $48 \mathrm{hrs}$ and $72 \mathrm{hrs}$ ). Each experiment was carried out with triplicates and the results were subjected to one way ANOVA. Complete inhibition of growth of pathogen was observed with ethanol extracts of all tested plant extracts. Unfortunately, the mycelial growth of tested fungi were induced by water extracts of tested plants and their potential effects differ significantly $(\mathrm{p}<0.05)$ among them. Water extracts of Vernonia cinerea, Phyla nodiflora and Cassia fistula significantly induced the growth of tested fungi while the remaining tested water extracts exhibited lower growth rate. Moreover, the diameter of fungal mycelium increased within the incubation period of fungi when tested with water extracts of plant leaf material. Fortunately, all tested ethanol extracts of leaves revealed complete inhibitory effect against tested nail fungus. However further purification and characterization of the bioactive components from these extracts may provide better understanding of bioactivity of these extracts.
\end{abstract}

Keywords: Nail fungus, Medicinal herbs, Poison food technique

\section{Introduction}

Nail infections due to dermatophytes or yeast, and other fungi are common in temperate western countries, tropics and subtropics with a hot and humid conditions (Chi et al., 2005). Humid or moist environment, psoriasis, wearing socks and shoes and, longer exposure to fungi and diminished blood circulation are favorable to the development of nail diseases. Dermatophytes are most common causative organisms. Candida and non dermatophytic molds are also recorded 
(Westerberg et al., 2013). The most common symptom of a fungal nail infection is, the nail becoming thickened and discoloured (white, black, yellow or green). As the infection progresses the nail can become brittle with pieces breaking off and crumble at the edge and it may separate from the skin (www.nhs.uk/conditions/ fungal-nail-infection/pages /introduction. aspx). This disease condition is known as Onychomycosis. Candidal Onychomycosis is common in people who wet their toes and hands more frequently in water.

To cure the disease Clotrimazole, Miconozole like pharmaceuticals are being used. But accumulation of chemical remedies can cause negative impact in long term. So that people have to consider herbal medicine that have preventative properties. Therefore in this study five common medicinal plants were selected to find out their potential in controlling onychomycosis pathogen.

\section{Objective}

To isolate the pathogen causing Onycho mycosis and to find out potential herbal remedy to control nail pathogen.

\section{Materials and Methods Isolation of fungi}

Fungal pathogen was isolated from diseased person on nail medium BD Dermatophyte Test Medium Agar. Scaly nail with yellow colour patches (Plate 1) was used to this and standard tissue isolation procedure was followed to isolate the pathogen. The infected nail parts were surface sterilized with 1:1000 mercuric chloride solution for 30 seconds and repeatedly washed in sterilized water three times to remove the traces of mercury and then transferred to selective nail medium (consisting of Papaic Digest of Soybean
Meal - 10 g, Glucose-10 g, Phenol Red - 0.2 g, Cycloheximide $-0.5 \mathrm{~g}$, Gentamicin $-0.1 \mathrm{~g}$, Tetracyclin- $\mathrm{HCl}-0.1 \mathrm{~g}$, Agar $-20 \mathrm{~g}$ in 1 liter and the $\mathrm{PH}$ was adjusted to $5.5 \pm 0.2$ ) under aseptic condition. The petri dishes were incubated at room temperature $\left(30^{\circ} \mathrm{C}\right)$ for 4 days and its morphological features were studied using light microscope.

Pure culture of nail pathogen was obtained and it was transferred to nail medium slants and incubated at room temperature for 4 days. Then that pure culture slants were used for further studies.

\section{Preparation of plant extracts}

The healthy plant leaves were collected from different area of Jaffna peninsula, Sri Lanka. They were dried in shade. Completely dried leaves were ground into fine powder using an electric blender. The powder was used to get water and ethanol extracts as described below (Jeyaseelan et al., 2010).

\section{Water and Ethanol extracts}

Twenty gram powder was soaked in $60 \mathrm{ml}$ sterile water and ethanol separately with intermittent shaking for one hour at ambient temperature. These mixtures were filtered through doubled layer muslin cloth and the filtrate was further filtered through Whatman No. 1 filter paper. The filtrate was completely dried in an oven at $45^{\circ} \mathrm{C}$.

\section{Determination of antifungal activity by poison food technique (Nene et al., 2002)} Sterile solidified nail media plates were prepared. Then dried product of leaf extracts of each plant were dissolved in water and ethanol respectively. $0.1 \mathrm{ml}$ of each extract was transferred onto the centre of sterile media plates separately and spread by using sterile glass spreader. Five days 
old nail fungal culture is punched aseptically with a sterile cork borer of $8 \mathrm{~mm}$ diameter and placed on the centre of the plates separately, whereas nail media plate was spread with $0.1 \mathrm{ml}$ clotrimazole and distilled water were maintained as (+) ve and (-) ve control respectively. Finally all plates were incubated at room temperature for 3-4 days and diameter of fungal growth was measured separately. Percentage inhibition of mycelia growth is evaluated by comparing the colony diameter of poisoned plate (with plant extract) and non-poisoned plate (with distilled water) and calculated using the formula given below (Phasuda et al., 2007).

$$
\underset{\text { Inhibition }}{\% \text { Mycelial }}=\frac{\mathrm{D}_{\mathrm{c}}-\mathrm{D}_{\mathrm{t}}}{\mathrm{D}_{\mathrm{t}}} \times 100
$$

where:

$\mathrm{D}_{\mathrm{c}}=$ diameter of control

$\mathrm{D}_{\mathrm{t}}=$ diameter of test

Results were subjected to one way ANOVA

followed by LSD test.

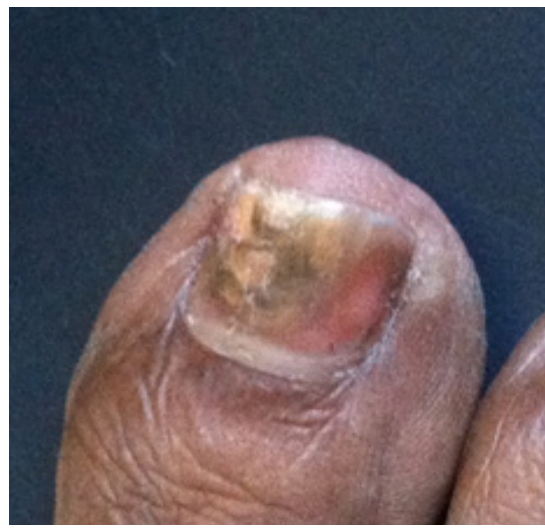

Plate 1: Infected toe nail wit discolored patches

\section{Results and Discussion}

All the tested water extracts showed active growth of fungi after 48 hours and 72 hours of incubation period whereas fungus exhibited better growth rate with increasing incubation period (Table 1). Among the leaf water extracts, Phylanodi flora, Aristolochia bracteolata and Lowsonia inermi showed better inhibitory effect compared with remaining extracts.

But, complete inhibition of growth of pathogen was obtained with ethanol extracts of all tested leaf materials. Although, the Clotrimazole (control) inhibit the pathogen, usage of that like chemical remedies may cause health and environmental hazards. Therefore the use of natural herbal remedies to cure the diseases is more preferred.

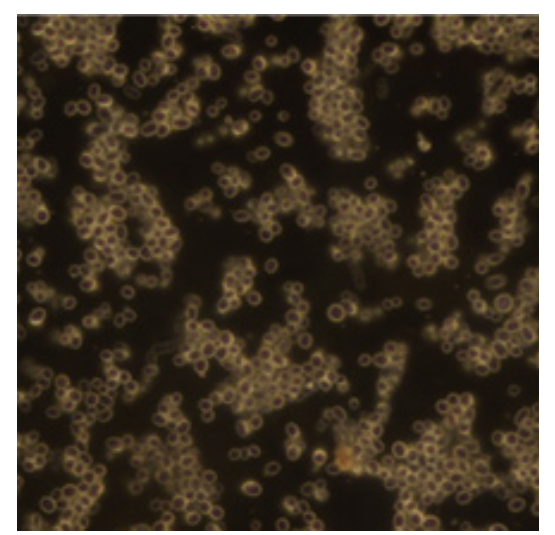

Plate 2: Colonial morphology of yeast under microscope x 400 


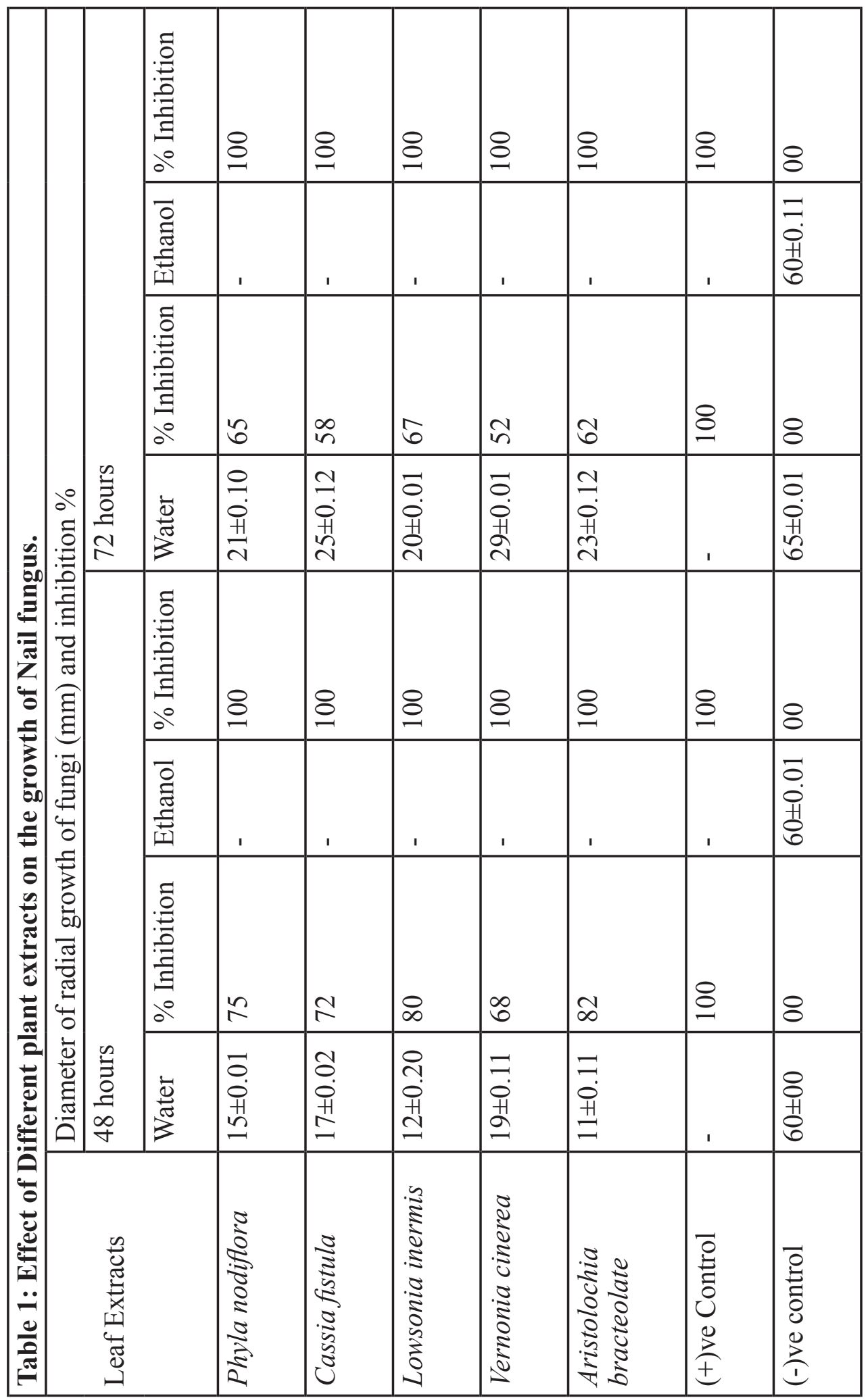




\section{Conclusion}

From the morphology it was confirmed that the pathogen isolated from the infected nail is Candida sp. (Hyaline, one - celled, form short chains by budding) - Plate 2. In this study, all tested ethanol extracts of leaves of all plants revealed complete inhibitory effect against tested nail fungus. On the other hand, the water extracts induced the growth of all tested fungi with increasing incubation period. Therefore, further purification and characterization of the bioactive components from these extracts may provide better understanding of bioactivity of these extracts. This study revealed the possibility of using ethanol extracted compounds in the preparation of herbal based products for tropical application to the nail. Chemical remedies may cause health and environmental hazards. So we will be able to overcome these problems by using the natural herbal medicines that cure the diseases more effectively without side effects.

\section{References}

Chi CC, Wang,S.H. and Chou, M.C. 2005. Mycoses. 48(6): 413-20.

Jeyaseelan E.C., Pathmanathan M.K. and Jeyadevan J.P. (2010). Archives of Applied Science Research, 2(6): 325-331.

Nene, Y. Thapliyar, L. (2002). Poison food technique of Fungicides in plant disease control. Oxford and IBH publisher house, New Delhi. 425 pp.

Phasuda, J. and Varipat, A. (2004). J. Ethnopharm., 94: 49-54.

Westerberg, D. P., Voyack, M. J. (2013). Am. Fam. Physician (Review). 88(11): 762-70. 